Purdue University

Purdue e-Pubs

\title{
Introducing Concept Maps in Undergraduate Thermodynamics
}

Jessie Lofton

University of Evansville, jb363@evansville.edu

Follow this and additional works at: https://docs.lib.purdue.edu/aseeil-insectionconference

Part of the Mechanical Engineering Commons, and the Thermodynamics Commons

Lofton, Jessie, "Introducing Concept Maps in Undergraduate Thermodynamics" (2019). ASEE IL-IN Section Conference. 1.

https://docs.lib.purdue.edu/aseeil-insectionconference/2019/classroom/1

This document has been made available through Purdue e-Pubs, a service of the Purdue University Libraries. Please contact epubs@purdue.edu for additional information. 


\title{
Introducing Concept Maps in Undergraduate Thermodynamics
}

\begin{abstract}
Concept maps, also called mind maps, are a widely utilized educational tool. While numerous studies cite the benefits of concept mapping as a tool for student learning, the use of concept maps is more common in non-engineering disciplines. This study examines student perceptions and academic performance in an undergraduate, introductory Thermodynamics course for students majoring in Mechanical Engineering. The pedagogical approach includes incorporating student-developed concept maps, as well as an interactive study tool for First Law analysis that was derived from an instructor-developed concept map. Qualitative and quantitative results are presented. Results are limited to a single institution and a small sample size of students. Future work will expand the data set and include multiple institutions.
\end{abstract}

\section{Introduction}

Concept maps, mind maps, knowledge maps, and variations of such are graphical tools that represent knowledge, or information, in an organized fashion [1-4]. Mapping requires the identification of relationships between various concepts, often shown by connecting lines or arcs in the visual representation. While concept mapping was introduced as an educational tool more than thirty years ago, it has recently received more attention in STEM (science, technology, engineering and mathematics) disciplines [5-7].

Past studies have used concept mapping both as a tool to assess student learning and as a tool to improve student comprehension and retention of course content. While results from numerous studies have demonstrated gains in student comprehension and retention of course material, some disagreement surrounds the use of concept mapping as an assessment tool [8-11]. Johnstone and Otis suggest that concept maps should be treated as "very personal learning tools" due to the many necessary inferences that must be made in understanding a map and the corresponding opportunities for mistakes [12]. Accordingly, the concept maps created by students were not formally assessed or graded in the current study. This decision was also influenced by the acknowledgement of differing levels of motivation and pedagogical preferences among students.

Descriptions of pedagogical approaches incorporating concept mapping are more readily available in the literature for mechanics courses in the mechanical engineering curriculum than thermal science courses [11, 13-15]. There are a few studies related to thermodynamics within a chemistry curriculum $[6,16]$, but publications are scant regarding the adoption of concept mapping as a pedagogical approach in thermodynamics courses within a mechanical engineering program. The current study provides preliminary results for introducing concept maps in an undergraduate thermodynamics course for mechanical engineering students.

In the current study, the instructor presents students with an interactive PowerPoint file for $1^{\text {st }}$ Law analysis that is based on the instructor's concept map for the $1^{\text {st }}$ Law of Thermodynamics. Students are asked to develop personal concept maps for the $1^{\text {st }}$ Law of Thermodynamics and to continue adding topics as the course progresses. Both qualitative and quantitative results from student surveys are presented and discussed. 


\section{Methods}

Students in an introductory Thermodynamics course were presented with concept mapping as a learning tool in Fall 2018. Thirteen students were enrolled in the course, which is planned for the junior year of the mechanical engineering curriculum at the University of Evansville. The University of Evansville is a small, private regional university in the Midwest with a total enrollment of approximately 2500 students. Two students in the Thermodynamics course were female; four students were international. Additional demographic information was not collected.

Student mastery of course content was evaluated via homework, quizzes, in-class activities, and four exams. The exams were necessarily cumulative, as course content continues to build in complexity, but each exam focused on key concepts from recent lectures. Primary concepts for each exam are listed in Table 1. Permitted reference materials on the exam included the textbook and an individual equation sheet created by the student.

Table 1: Primary exam concepts

\begin{tabular}{|l|l|}
\hline & Key Topics \\
\hline Exam 1 & $\begin{array}{l}\text { Determining thermodynamic properties } \\
\text { Drawing \& labeling phase diagrams } \\
\text { Evaluating thermodynamic work }\end{array}$ \\
\hline Exam 2 & $\begin{array}{l}1^{\text {st }} \text { Law Analysis } \\
\text { Conservation of mass } \\
\text { Identifying thermodynamic systems }\end{array}$ \\
\hline Exam 3 & $\begin{array}{l}2^{\text {nd }} \text { Law Analysis } \\
\text { Entropy accounting } \\
\text { Isentropic efficiencies and relations }\end{array}$ \\
\hline Exam 4 & $\begin{array}{l}\text { Power Cycles } \\
\text { Psychrometrics } \\
\text { Ideal Gas Mixtures }\end{array}$ \\
\hline
\end{tabular}

The instructor introduced concept mapping in the classroom after covering the material for the first exam. After reviewing the concepts for Exam 1, an expanded $1^{\text {st }}$ Law equation was written on the board to demonstrate the goals for Exam 2. Below the equation, a concept map entry was created for "1 1 st Law: Conservation of Energy," which was then connected to a new entry for "Properties." Students were asked to suggest new concept map entries that could be connected to "Properties" based on knowledge acquired for Exam 1. This very limited concept map introduced students to the tool and provided some scaffolding to allow students to develop their own concept maps. The example was intentionally limited to avoid overly influencing the student maps.

A short discussion followed to share with students the learning benefits of concept mapping. Students were encouraged to begin developing, and to continue updating, their own concept maps. Emphasis was placed on the map being a personal learning tool. Students were encouraged to begin their own maps before discussing with their peers, if they chose to collaborate at a later time. It was clearly stated that each concept map could be quite different, and that no single 
concept map existed as 'the correct answer.' The goal was described as building connections, while adding and organizing topics in a way that made sense to the creator of the map.

Following the discussion of concept map development, the $1^{\text {st }}$ Law Interactive PowerPoint (v.1.0), or FLIP was introduced with instructions for access and use. FLIP was described as an interactive concept map combined with a $1^{\text {st }}$ Law analysis flow chart. Students were encouraged to download FLIP for use as a study tool, as well as a homework aid.

\section{Concept Map Development}

Students were encouraged to begin developing concept maps when introduced to the $1^{\text {st }}$ Law of Thermodynamics. The concept maps were not an evaluated assignment. However, concept map development was posted on the course website with assigned homework problems. Students requested access to their concept maps on exams and quizzes; the request was granted with caveats of the concept map being limited to a single $8.5 \times 11$ inch page and not looking like a continuation of the permitted personal equation sheet.

The instructor did not provide a completed concept map as an example, but promised to present a further developed map after covering the course content required for $1^{\text {st }}$ Law analysis. Students were informed the intentions for not providing a sample concept map were to allow them to make their own connections and organize their own thoughts in a way that was helpful for them. The instructor was available for questions and discussion as students engaged in the process.

By providing the example concept map at the end of $1^{\text {st }}$ Law coverage in the course, the instructor minimized initial influence on student maps. The presentation of the instructor's map allowed students to compare their results with a subject matter expert, providing an opportunity for students to identify misconceptions or missed connections and make revisions.

\section{Interactive Concept Map - $1^{\text {st }}$ Law Study Tool}

The $1^{\text {st }}$ Law Interactive PPT, FLIP, was developed using a concept map centered on the general mathematical statement for an open, transient control volume. The goals for FLIP were to (1) act as a study aid and review tool for students to use at their own pace, (2) provide some scaffolding for systematically evaluating the $1^{\text {st }}$ Law equation, (3) reinforce appropriate assumptions and resulting simplifications when analyzing a thermodynamic system.

When developing FLIP, considerations were made for variations in student understanding. Hyperlinks were incorporated to allow users to move easily between topics, as needed, rather than reviewing every variable in the equation each time FLIP was accessed. With hyperlinks, students could choose which variables, if any, they needed additional help evaluating. FLIP would then direct the student to a new screen, showing how the selected variable can be evaluated, before returning to the equation with the option of selecting a new variable.

Version 1.0 of FLIP was distributed in Fall 2018 with no apparent issues. However, to properly use FLIP, it must be opened in presentation mode of PowerPoint, which hinders accessibility. Due to the physical structures in the classroom where the course was taught in Fall 2018, significant inconveniences prevented the instructor from demonstrating use of FLIP while solving example problems in class. Also, the majority of students at the University of Evansville 
do not bring laptops to class, which limited student access during class meetings. Future versions of FLIP will, ideally, be easily accessible on a smartphone for accessibility and convenience.

The following example shows how a user might navigate FLIP to solve a closed, transient thermodynamic system. After the title slide, users are provided information for navigating FLIP, including 'buttons' to look for with hyperlinks, as shown in Figure 4.

(current version: v.1.0)

\section{About :}

This is an interactive PowerPoint designed to be a study tool for

It must be viewed in Presentation mode for the hyperlinks and animations to work.

Clickable buttons will usually be highlighted as a gray box

\section{Click me!}

There will also be options to return to the previous or return to the home slide

Sometimes you can hover the mouse over variables for hints Hover Here!

If you notice any errors, broken links, or opportunities for improvement, please contact with your feedback.

Limitations for use (assumptions)

- The following equations are simplified for a single fluid

- Steady/uniform rates of heat transfer, work, and mass flow

- Uniform properties

Figure 4: FLIP slide providing user instructions

The next slide, Figure 5, directs user to identify the thermodynamic system of interest. A written description and mathematical representation of the $1^{\text {st }}$ Law are provided, as well as links to animations from the textbook used in the course.

\section{$1^{\text {st }}$ Law of Thermo (Conservation of Energy)}



Figure 5: General $1^{\text {st }}$ Law statement and beginning of interactive analysis 
After clicking the "CLOSED" button to identify the system, the user is redirected to a new slide, shown in Figure 6, with a $1^{\text {st }}$ Law equation that has been simplified for a closed system assumption. The user is prompted to decide whether the system is operating at steady state conditions or transient conditions.

$$
1^{\text {st }} \text { Law - Closed System }
$$$$
\frac{d E_{C V}}{d t}=\delta Q_{C V}-\delta W_{C V}
$$
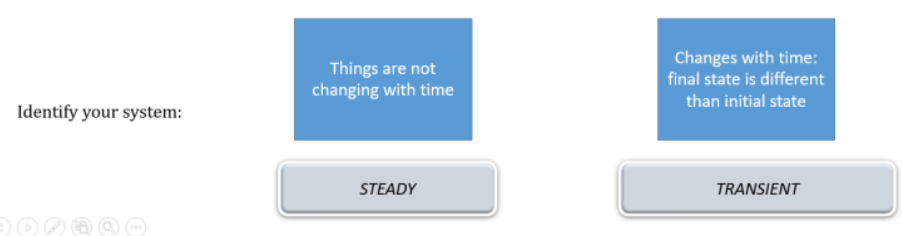

Figure 6: Simplified analysis for a closed system

After clicking the "TRANSIENT" button, the user is taken to a new, animated slide that steps through the expansion of the $1^{\text {st }}$ Law equation. Each equation in Figure 7 appears on a subsequent click of the mouse, and the slide title acts as a reminder of the simplifying assumptions thus far applied.

$$
\begin{aligned}
& 11^{\text {st }} \text { Law }- \text { Closed System, Transient } \\
& \frac{d E_{C V}}{d t}=\delta Q_{C V}-\delta W_{C V} \\
& E_{2, C V}-E_{1, C V}={ }_{1} Q_{2}-{ }_{1} W_{2} \\
& m_{2}\left(u_{2}+\frac{V_{2}^{2}}{2}+g z_{2}\right)-m_{1}\left(u_{1}+\frac{V_{1}^{2}}{2}+g z_{1}\right)={ }_{1} Q_{2}-{ }_{1} W_{2}
\end{aligned}
$$

Figure 7: Expanded analysis for a closed, transient system (slide 1 of 2)

The final form of the simplified equation appears on the following slide, where the user then has several options to proceed. By hovering the mouse over any of the variables in the final equation, dialog boxes will appear with hints for evaluating, as shown with the conversion factor reminder for the kinetic energy term in Figure 8. 


$$
\begin{aligned}
& 1^{\text {st }} \text { Law - Closed System, Transient (cont'd) } \\
& { }_{1} Q_{2}+m_{C V}\left(u_{1}+\frac{V_{1}^{2}}{2}+g z_{1}\right)=m_{C V}\left(u_{2}+\frac{V_{2}^{2}}{2}+g z_{2}\right)+{ }_{1} W_{2} \\
& { }_{1} Q_{2}=m_{C V}\left(u_{2}-u_{1}\right)+m_{C V}\left(\frac{V_{2}^{2}-V_{1}^{2}}{2}\right)+m_{C V} g\left(z_{2}-z_{1}\right)+{ }^{W_{2}} \\
& \begin{array}{l}
\text { What happened } \\
\text { to } m_{1} \text { and } m_{2} \text { ? }
\end{array} \begin{array}{c}
\text { If the system is } \\
\text { not accelerating, } \\
\text { there is no } \Delta K E
\end{array}
\end{aligned}
$$

Figure 8: Expanded analysis for a closed, transient system (slide 2 of 2)

If the user needs help evaluating properties or energy transfer due to work, clicking the corresponding button will transition to a new slide. Clicking the thought bubble on this slide would redirect to a slide showing an appropriate simplification of the continuity equation. In this example, if the user wanted to determine how to evaluate the change in internal energy, Figure 9 would appear after clicking the button surrounding $\left(u_{2}-u_{1}\right)$.

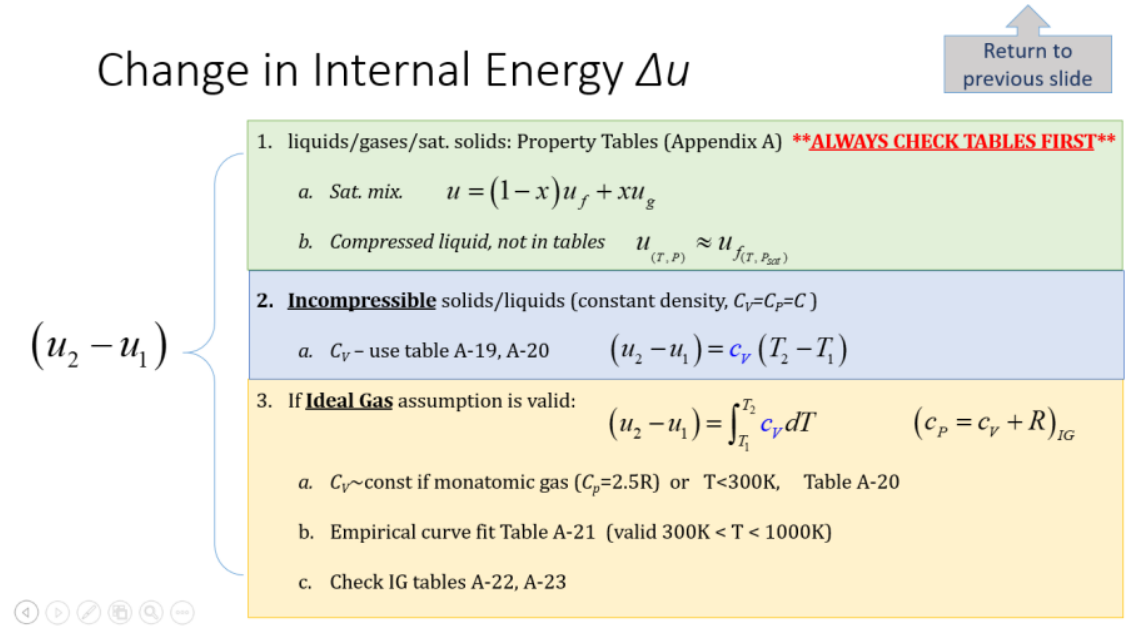

Figure 9: Optional slide for help evaluating changes in internal energy

The slides providing additional help for evaluating specific terms could prove especially beneficial to students struggling with course content. The slide shown in Figure 9 provides the user with various cases for evaluating the property and directs them to the appropriate tables in the course textbook.

After learning, or confirming, how to evaluate the change in properties, the user can click the "return to previous slide" button in the upper righthand corner to return to the simplified $1{ }^{\text {st }}$ Law statement, or Figure 8. Once returned, the user can follow similar steps to evaluate as many of the remaining variables as desired. Satisfied in their understanding of the problem, the user can then return to the general $1^{\text {st }}$ Law definition and begin defining a new system using the button pictured in Figure 10. 


\section{End of: \\ closed system, transient}

Figure 10: Final slide for closed, transient system analysis

The goal of the many options in FLIP was to allow students to review course material at their own pace. Some students may only want to confirm they have appropriately simplified the equation and listed the corresponding assumptions. Some students may want to review how to evaluate each variable in the equation. FLIP allows the students to choose how much helpful information they want to receive. Ideally, students would use FLIP as a study tool to gain confidence and boost self-efficacy while improving their understanding at their own pace. Not all students are comfortable asking many questions, so FLIP also provides students a safe place to question their understanding and correct their mistakes.

\section{Results}

Three samples of student generated concept maps that were submitted with Exam 2 are provided in Figures 1-3.

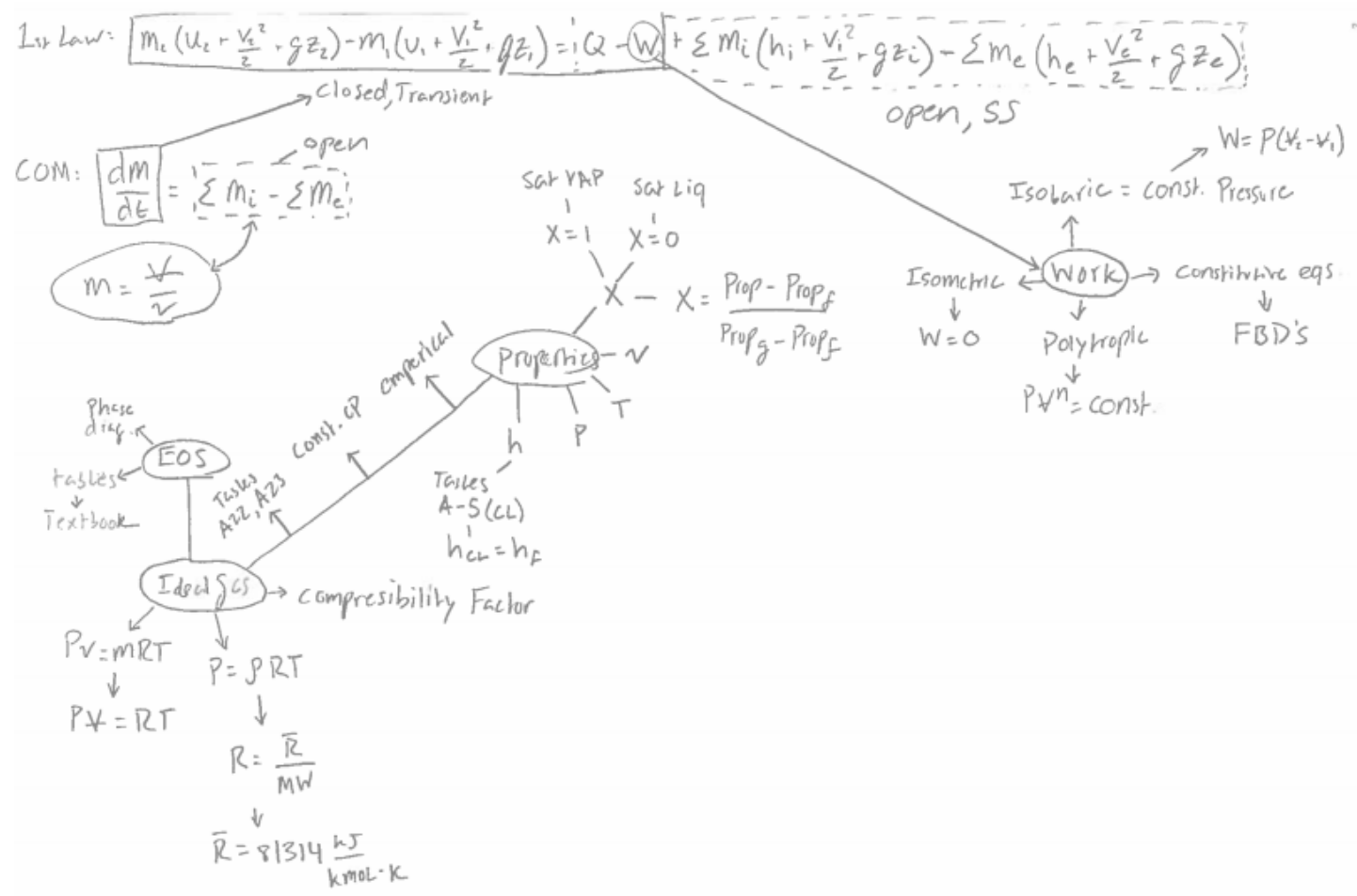

Figure 1: Concept map developed by Student A 


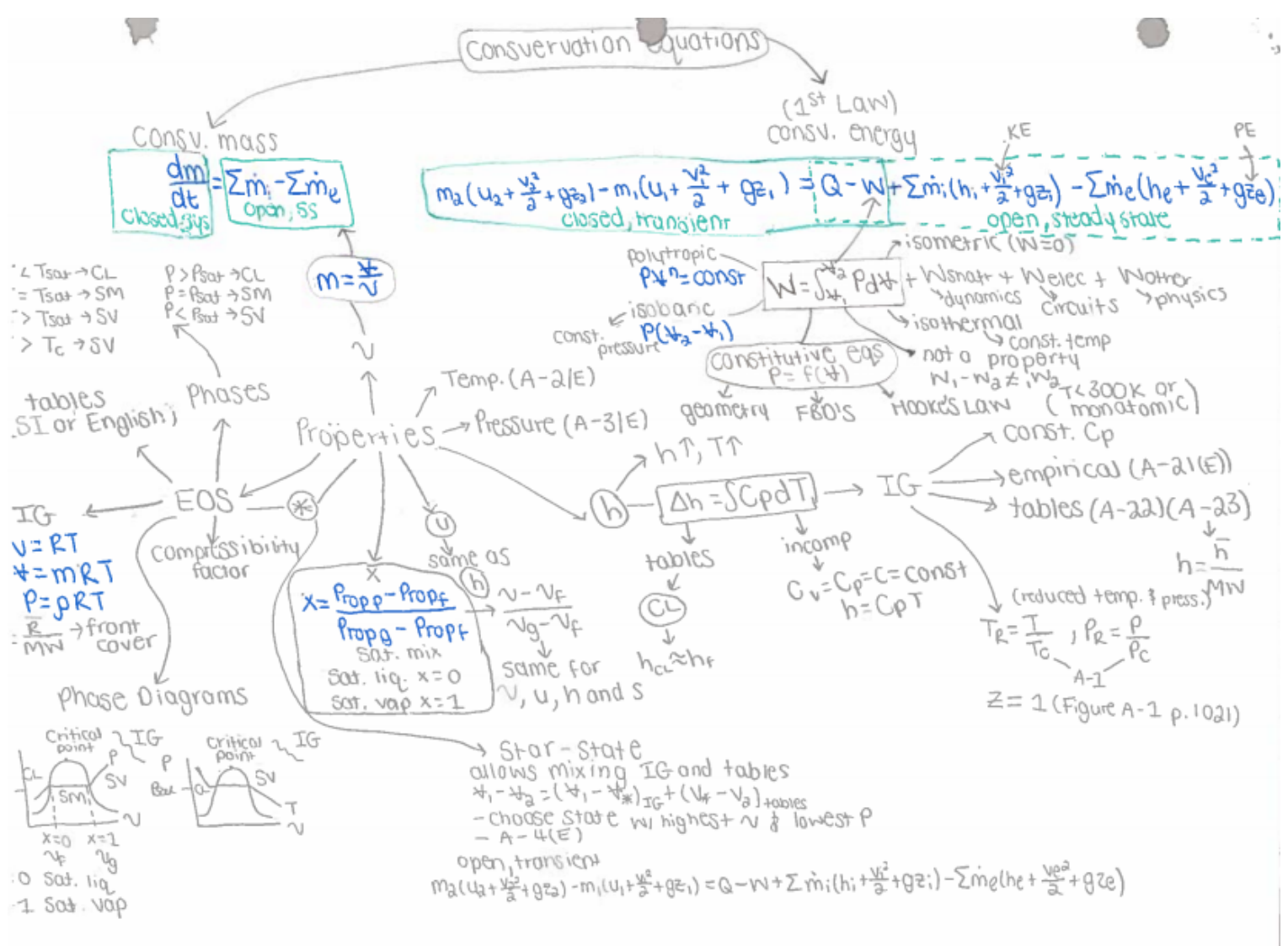

Figure 2: Concept map developed by Student B

Somewhat surprisingly, there was no clear connection to between fluid properties and the conservation equations on the map developed by Student A. Perhaps the student did not feel compelled to graphically include the link as fluid properties are necessary for every equation in Thermodynamics. The concept map developed by Student B utilized color coding and included more detail than Student A. Student B also chose to include images of phase diagrams with the concept entry. The map developed by Student $\mathrm{C}$ included sign convention for work and heat transfer, which was not indicated on maps from students A and B. A few students submitted concept maps with no differences from the example presented in class, but generally the maps each had some customization. 


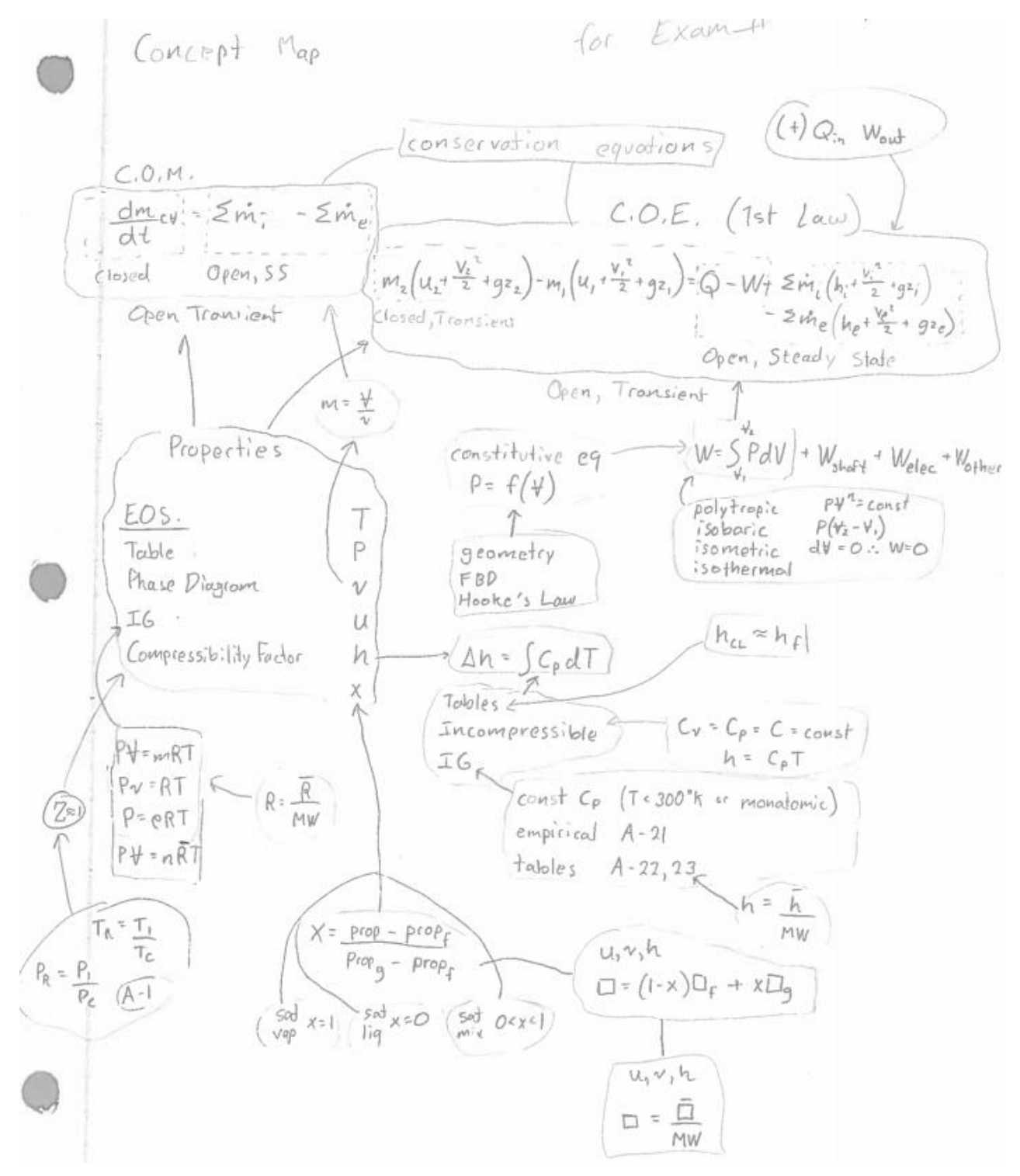

Figure 3: Concept map developed by Student C

Some obvious similarities can be found in all three examples. The similarities are likely due to the instructor developing a concept map in class prior to Exam 2. Before demonstrating the process of how the instructor might build a concept map, students had been given several opportunities to use their personal maps when completing course assignments. After covering the required content for Exam 2, the instructor invited students to update their personal maps before building an example map in class. Many students appeared to be modifying their maps to better match the concept map presented by the instructor, which led to more similarities between maps.

\section{Student Feedback - Survey Results}

An optional survey was distributed to students during the final week of the semester. The survey consisted of ten Likert Scale prompts related to concept maps and four prompts related to the FLIP. Students could respond with values 1-5, where ' 1 ' corresponded to strong disagreement, and ' 5 ' corresponded to strong agreement. A 'not applicable' response option was also provided. 
Twelve of the thirteen students enrolled in the course completed the survey. The results are summarized in Table 2 in the form of average response, with a representative histogram.

Table 2: Summary of Student Survey Responses $(n=12)$

\begin{tabular}{|c|c|c|}
\hline & Prompt & Average Response \\
\hline \multirow{10}{*}{ 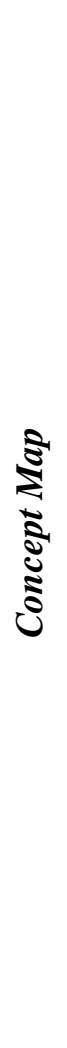 } & I was familiar with concept maps before this course & 2.00 \\
\hline & $\begin{array}{l}\text { I have used concept maps as a study tool in my engineering } \\
\text { courses prior to this course }\end{array}$ & 1.62 \\
\hline & I will use concept maps as a study tool in the future & 3.08 \\
\hline & $\begin{array}{l}\text { I began my personal concept map before the instructor } \\
\text { presented hers }\end{array}$ & 2.62 \\
\hline & $\begin{array}{l}\text { Developing a concept map was beneficial to my learning in } \\
\text { this course }\end{array}$ & 3.23 \\
\hline & $\begin{array}{l}\text { I modified my concept map based on discussions with } \\
\text { classmates }\end{array}$ & 3.31 \\
\hline & The concept map was a useful resource for homework & $3.08^{*}$ \\
\hline & $\begin{array}{l}\text { The concept map was a useful resource for quizzes/in-class } \\
\text { activities }\end{array}$ & 3.31 \\
\hline & The concept map was a useful resource for exams & 3.54 \\
\hline & I would prefer the course to be taught without concept maps & 2.15 \\
\hline \multirow{4}{*}{$\underset{3}{\mathbb{E}}$} & $\begin{array}{l}\text { The Interactive } 1^{\text {st }} \text { Law PPT was beneficial to my learning in } \\
\text { this course }\end{array}$ & $3.90^{* * * *}$ \\
\hline & $\begin{array}{l}\text { I would use a mobile app version of the } 1^{\text {st }} \text { Law PPT, if } \\
\text { available }\end{array}$ & 3.31 \\
\hline & The $1^{\text {st }}$ Law PPT was a useful resource for homework & $3.80^{* * *}$ \\
\hline & $\begin{array}{l}\text { I do not benefit from electronic study tools like the } 1^{\text {st }} \text { Law } \\
\text { PPT }\end{array}$ & 2.31 \\
\hline
\end{tabular}

Students were also asked to estimate the number of times they accessed FLIP during the semester. Responses are summarized in Table 3. 
Table 3: Self-reported student use of FLIP, $(n=12)$

\begin{tabular}{|c|c|}
\hline Response & Frequency \\
\hline Never & $8.3 \%$ \\
\hline $1-5$ times & $50.0 \%$ \\
\hline 5-10 times & $33.3 \%$ \\
\hline 10+ times & $16.7 \%$ \\
\hline
\end{tabular}

Eight students chose to provide additional comments in a survey space reserved for optional open response. Verbatim comments are provided below.

1) I did not use the $1^{\text {st }}$ Law PPT but I see it as a really useful resource for some people.

2) Tools such as the concept map and interactive powerpoint are a great idea! I wish I would have utilized them sooner and more frequently. Hopefully other engineering courses begin to implement learning tools such as these. That would be extremely beneficial.

3) The interactive $1^{\text {st }}$ Law PPT was helpful once I knew how to use it. It was confusing in the beginning but it became more beneficial as we learned more in class. The PPT also helped me develop my concept map.

4) It would be better to have chapter-wise concept map. If we make it at the end of every chapter, we will have better understanding of the concepts. Interactive $1^{\text {st }}$ Law PPT was really useful for me to differentiate between types of systems.

5) They were helpful; however, applying them solving problems in class would be of much help.

6) Both the concept map and the PPT were very helpful.

7) Concept maps are a great resource, but only if you compartmentalize the concepts. Perhaps it would be beneficial to start with the big picture then narrow focus on particular aspects.

8) I used the $I^{\text {st }}$ Law PPT for the first couple homeworks but then I had it memorized and didn't use it after that.

While the open response comments were generally positive, there were a few suggestions for improving the incorporation of concept maps or FLIP that will be used in the future. Using FLIP alongside examples in the classroom makes sense, if the physical setup of the classroom allows. Unfortunately doing so was too cumbersome in the classroom used during this study. The suggestion to develop concept maps for each chapter will also be considered for continuations of 
this work. Revisiting the concept map for each chapter may provide additional scaffolding for students to reflect on new concepts and immediate connections before linking the material to content from previous chapters.

A few students also provided positive, unprompted feedback, regarding the concept maps or FLIP, on the university's end-of-semester student evaluation forms. In response to the open response question, "What about this course has helped you learn? What are the major strengths of the course?" one student submitted the following feedback. "I believe the interactive concept map was super cool and made learning about thermodynamics fun. I would love to the alpha version that covers the entire course from properties to diesel combustion engines. I would encourage speaking with other professors to make more interactive concept maps that could link up with the one for thermodynamics, in particular, fluids, combustion and heat transfer." The student comments highlight positive impacts from the learning tools.

\section{Instructor Feedback}

Students were generally receptive to incorporating concept maps. A few students chose to use their concept map as their only reference on the exams, whereas one student chose not to use a concept map at all on exams. Assigning the development of concept maps as an optional activity allowed students some autonomy, which likely lent to a more positive experience in the course. Students seemed to understand the potential benefits and purpose of the exercise, which bolstered motivation. On the day of the first quiz where the concept maps would be allowed as a reference, the instructor observed evidence of student collaboration upon entering the engineering building that morning. A whiteboard was filled with a detailed concept map that students had clearly been building and revising the previous evening. It was rewarding to see the effort exerted by students, as well as the numerous connections that students had identified between course topics.

Due to the small sample size, it is difficult to make any statistically significant claims regarding the impact of the concept maps on student performance. Anecdotally, the students seemed more engaged in class. Submitted work seemed more uniform in the logical progression of solutions. It is unclear if the concept maps or FLIP provided extra scaffolding that led to more organized thought processes and logical solution procedures, but that was an intended outcome. While not all students benefited equally from the incorporation of concept maps, no negative impacts were noted. The new study tools seemed to have the biggest impact, and heaviest use, for students that found the course content more challenging. Future offerings of the course will continue to include concept maps and FLIP as optional study tools. The impacts tend to be either very positive for students that find the tools useful, or neutral for students that choose not to invest time in the new study tools. 


\section{Implications and Conclusions}

The current study was limited to a single institution and a small sample size of students. Conclusions are primarily qualitative and anecdotal due to limitations in achieving statistical significance with qualitative results. Future work will extend the study, and increase the sample size to gather more quantitative, as well as qualitative, data. Acknowledging the limitations to the study, the results still indicate positive impacts that support the adoption of concept maps and FLIP as study tools in an undergraduate thermodynamics course.

Student survey responses indicated positive (averaged) outcomes for all prompts regarding impacts of incorporating concept maps and FLIP. The strongest responses indicated both tools as beneficial for student learning. Weaker responses often corresponded to prompts with primarily neutral responses, as seen in the histograms. The results indicate that positive impacts outweigh any negative impacts from incorporating the study tools. In fact, no students complained about the new approach. A few suggestions were provided in the survey for improving the student experience, such as using the tools more frequently as instructional aids and developing concept maps for each chapter in the textbook.

Student thoughts appeared to be more organized in submitted solutions, which indicates the tools provided additional scaffolding for students to link topics and demonstrate logical analytical processes. The concept maps also required students to reflect on their learning and their own thought process, which is valuable in itself. Some students indicated a desire to continue building the concept map to link content from other courses; this result implies that developing a concept map for a single course can lead students to making more connections across courses rather than compartmentalizing each class as a separate, or unrelated, area of study. Future work will incorporate concept maps for additional courses.

The goals for FLIP to (1) act as a study aid and review tool for students to use at their own pace, (2) provide some scaffolding for systematically evaluating the $1^{\text {st }}$ Law equation, and (3) reinforce appropriate assumptions and resulting simplifications when analyzing a thermodynamic system were met. Some students relied more heavily on FLIP, accessing it multiple times. Other students used FLIP on a more limited basis. Students were also better at consistently identifying all simplifying assumptions required for a thermodynamic analysis than in traditional offerings of the course.

Based on the student feedback, FLIP should be made available to students in future offerings of the course as an independent study aid. Demonstrating FLIP with early example problems in class is recommended. FLIP is significantly beneficial to struggling students, which could improve self-efficacy as well as retention rates. The author plans to make the tool more widely available after further development and refinement. Future iterations of FLIP could increase accessibility and extend the content to additional thermodynamic topics. 


\section{References}

[1] Plotnick, E. (1997). Concept Mapping: A Graphical System for Understanding the Relationship between Concepts. Retrieved from http://www.mind-mapping.org/seminalpapers-in-information-mapping/conceptmapping-overview.html

[2] Wheeldon, J., \& Faubert, J. (2009). "Framing experience: Concept maps, mind maps, and data collection in qualitative research." International Journal of Qualitative Methods, 8(3), 68-83.

[3] Turns, J., Atman, C. J., \& Adams, R. (2000). “Concept maps for engineering education: A cognitively motivated tool supporting varied assessment functions." IEEE Transaction on Education, 43(2), 164-173.

[4] Wycoff, J. (1991). Mindmapping: Your personal guide to exploring Creativity and problem-solving. New York, NY: Berkly Books

[5] Lopez, E., Kim, J., Nandagopal, K., Cardin, N., Shavelson, R. J., \& Penn, J. H. (2011). "Validating the use of concept-mapping as a diagnostic assessment tool in organic chemistry: implications for teaching." Chem. Educ. Res. Pract., 12, 133-141.

[6] Enszer, J. A. (2018). "WIP: Exploring Mind Maps for Assessment in an Introductory Chemical Engineering Course.” Proceedings 2018 ASEE Annual Conference, Salt Lake City, UT.

[7] Ferguson, S. M., Foley, R. W., Eshirow Jr., J. K., \& Pollack, C. C. (2018). "Refining Concept Maps as Method to Assess Learning Outcomes Among Engineering Students." Proceedings 2018 ASEE Annual Conference, Salt Lake City, UT.

[8] Daugherty, J. L., Custer, R. L., and Dixon, R. A. (2011) "The Use of Concept Mapping to Structure a Conceptual Foundation for Secondary Level Engineering Education,” 2011 ASEE Annual Conference, Vancouver, BC.

[9] M.J.S. Roth and K.L. Sanford Bernhardt, (2016) "Using Concept Maps for Assessment and Improvement of a Multi-Section Introduction to Engineering Course," Proceedings 2016 ASEE Annual Conference, New Orleans, LA.

[10] Kinchin, I. M. (2000b). "Concept mapping in biology.” Journal of Biological Education, 34(2), 61-68.

[11] Fang, N. (2015) 'Using Student-Generated Concept Maps to Assess Students' Conceptual Understanding in a Foundational Engineering Course," Proceedings 2015 ASEE Annual Conference \& Exposition, Seattle, WA.

[12] Johnstone, A. H. and Otis, K. H., (2006) "Concept mapping in problem based learning: a cautionary tale," Chemistry Education Research and Practice, 7, 84-95.

[13] Pierre-Antoine, R., Sheppard, S. D., and Schar, M., (2014) "Utilizing Concept Maps to Improve Engineering Course Curriculum in Teaching Mechanics," Proceedings of the 2014 ASEE Annual Conference \& Exposition, Indianapolis, Indiana.

[14] Egelhoff, C. J., Podoll, N., and Tarhini, K., (2010) "Work in Progress - A Concept Map for Mechanics of Materials," Proceedings of the 40th ASEE/IEEE Frontiers in Education Conference, Washington, DC, October 27-30, 2010.

[15] Fang, N. (2016) "Using Concept Maps to Illustrate the Evolution of Key Concepts: Student Learning Experience in a Foundational Undergraduate Engineering Course," Proceedings 2016 ASEE Annual Conference, New Orleans, LA.

[16] Francisco, J. S., Nakhleh, M. B., Nurrenbern, S. C., \& Miller, M. L. (2002). "Assessing Student Understanding of General Chemistry with Concept Mapping." Journal of Chemical Education, 79 (2), 248 